\title{
PENGETAHUAN DAN SIKAP RESIDEN OBSTETRI DAN GINEKOLOGI TENTANG KESELAMATAN PASIEN DI KAMAR BERSALIN RSUP DR SARDJITO YOGYAKARTA
}

\author{
Fadhilah Armaijn, Ova Emilia, Irwan Taufiqur Rachman
}

\begin{abstract}
Background: The traditional medical Oath of 'first do no harm' is something that is very rarely breached either intentionally by a doctor, nurse or other health practitioner. Resident is health workers who perform services directly to patients that's why their knowledge and attitudes towards patient safety are very useful
\end{abstract}

Objective: To determine the relationship of the level of knowledge with the attitudes about patient safety in obstetrics and gynecology resident while services in delivery room at Dr DR Sardjito hospital.

Method: Descriptive methods with cross sectional approach, accompanied by a qualitative research The study involved 90 residents of Obstetrics and Gynecology at Sardjito Hospital Yogyakarta, by filling out a questionnaire. Knowledge assessed based on the number of correct answers and categorized into good and bad. Attitudes toward patient safety was assessed using a Safety Attitude Questionnaire (SAQ) labor and delivery version. Reliability was measured using Cronbach's alpha. The qualitative data collection (interviews) conducted to support the descriptive data.

Result and Discussion: Cronbach's Alpha value for $S A Q=0.862$, and the question of knowledge $=0.702$. Between 77 responden who had good level of knowlage, only $53,2 \%$ had a good level of attitudes, and between 13 who has bad level of knowlage, there were 10 responden with good level of attitudes $(76,9 \%)$ ( $R P$ P,69;95\% Cl $0,44-1,04 ; p=0,11$ ). Elements of stress recognition on the attitude were getting the lowest average value $(3.50 \pm 0.56)$. From the qualitative data were known that the resident had desire for a reduction in working hours as well as improved communication and collaboration between teams. Althogh most of resident had a good level of knowledge and attitudes about patient safety, there were no meaning because of $p$ value was $>0,05$ (OR 2,69;95\%Cl 0,66-10,9; $p=0,17$ ).

Conclusion: Clinically, a good level of knowledge about patien safety improving a good level of attitude towards patient safety.

Keywords: Knowledge- attitude- patient safety- resident obstetrics

\begin{abstract}
ABSTRAK
Latar Belakang: Sumpah medis tradisional 'first do no harm' (tidak merugikan) adalah sesuatu yang sangat jarang dilanggar dengan sengaja baik oleh dokter, perawat maupun praktisi kesehatan lainnya ${ }^{1}$. Residen merupakan tenaga kesehatan yang melakukan pelayanan langsung kepada pasien sehingga pengetahuan dan sikap mereka terhadap keselamatan pasien sangat berperan dan bermanfaat.

Tujuan: Untuk mengetahui hubungan tingkat pengetahuan dengan sikap tentang keselamatan pasien pada residen obstetri dan ginekologi dalam pelayanan di kamar bersalin RSUP DR Sardjito Yogyakarta.
\end{abstract}

Departemen Obstetri dan Ginekologi, Fakultas Kedokteran Universitas Gadjah Mada/

RSUP Dr. Sardjito Yogyakarta 
Metode: Metode deskriptif dengan pendekatan cross sectional disertai dengan penelitian kualitatif, diikuti 90 residen Obstetri dan Ginekologi.di RSUP Dr. Sardjito Yogyakarta dengan cara mengisi kuesioner. Pengetahuan dinilai berdasarkan jumlah jawaban yang benar dan dikategorikan menjadi baik dan buruk. Sikap terhadap patient safety dinilai menggunakan kuesioner Safety Attitude Questionnaire (SAQ) labor and delivery. Reliabilitas diukur dengan menggunakan alpha Cronbach. Pengumpulan data kualitatif (wawancara) dilakukan untuk mendukung data deskriptif.

Hasil dan Pembahasan: Nilai Alpha Cronbach untuk $S A Q=0,862$, dan pertanyaan pengetahuan =0,702 Terdapat 77 orang responden yang berpengetahuan baik, 41 diantaranya mempunyai sikap yang baik tentang patient safety $(53,2 \%)$, sedangkan diantara 13 orang responden yang berpengetahuan buruk tentang patient safety, terdapat 10 orang yang mempunyai sikap yang baik $(76,9 \%)(\mathrm{RP} 0,69 ; 95 \% \mathrm{Cl} 0,44-$ $1,04 ; p=0,11)$. Unsur pengenalan stress pada sikap mendapatkan nilai rata-rata terendah $(3,50 \pm 0,56)$. Dari data kualitatif diketahui adanya keinginan residen untuk pengurangan jam kerja serta perbaikan komunikasi dan kerjasama antar tim. Dengan nilai $p>0,05$ (OR 2,69;95\% Cl 0,66-10,9; $p=0,17$ ), hubungan pengetahuan dengan sikap menjadi tidak bermakna. Walaupun sebagian besar residen mempunyai pengetahuan dan sikap tentang keselamatan pasien yang baik.

Kesimpulan: Secara klinis, pengetahuan tentang keselamatan pasien yang baik meningkatkan sikap yang baik tentang keselamatan pasien pada residen obstetri dan ginekologi.

Kata kunci: Pengetahuan- sikap- patient safety- residen obstetri

\section{PENDAHULUAN}

Keselamatan pasien merupakan komponen esensial di dalam pelayanan kesehatan. Budaya keselamatan adalah budaya yang menerima bahwa bahkan tenaga kesehatan yang kompeten bisa berbuat salah tetapi tidak mentoleransi adanya perilaku yang sembarangan. ${ }^{1,2}$

Pada tahun 1999, diperkirakan terjadi kematian sebanyak 44.000-98.000 tiap tahunnya karena kesalahan medis. Sejak saat itu, timbul inisiasi untuk mencegah terjadinya kesalahan medis. $^{3}$

Upaya untuk meningkatkan pelayanan kesehatan bagi kelompokmasyarakatyang rentan, terutama wanita hamil, harus melalui proses yang dinamis. Ini termasuk memahami bahwa banyak wanita hamil yang tidak mendapatkan perawatan yang tepat dan merugikan, bahkan mengalami peristiwa yang iatrogenik saat mendapatkan perawatan medis dibawah standar.
Ini harus dilihat sebagai kegagalan sistem bukan kegagalan individu. ${ }^{4}$

Residen merupakan tenaga kesehatan yang melakukan pelayanan langsung kepada pasien. Di RSUP Dr. Sardjito Yogyakarta, residen obstetri dan ginekologi bekerja mulai dari pukul 6 pagi sampai pukul 4 sore, belum termasuk jika ada tindakan operasi yang belum selesai pada jam tersebut. Pada saat mendapat giliran jaga, residen akan selesai bekerja pada pukul 4 sore keesokan harinya. Jadi jika dijumlahkan lamanya residen jaga itu bekerja adalah 34 jam tanpa waktu istirahat untuk tidur. Sistem jaga itu sendiri tergantung jumlah residen yang ada. Besar kecilnya tanggung jawab perawatan dan penatalaksanaan pasien dibagi berdasarkan tingkatan residen. Oleh karena itu pengetahuan dan sikap mereka terhadap keselamatan pasien sangat berperan dan bermanfaat untuk melakukan pelayanan seperti pada pelayanan pasien di kamar bersalin. 


\section{METODE}

Penelitian ini menggunakan metode deskriptif dengan pendekatan cross sectional disertai dengan penelitian kualitatif. Penelitian dilakukan di RSUP Dr. Sardjito Yogyakarta pada periode 1 Januari 2014 hingga 31 Mei 2014. Pengetahuan tentang keselamatan pasien di kamar bersalin dinilai berdasarkan jumlah jawaban kuesioner yang benar dan dikategorikan menjadi baik dan buruk. Sikap terhadap patient safety dinilai menggunakan kuesioner Safety Attitude Questionnaire (SAQ) labor and delivery. Pengumpulan data kualitatif dilakukan untuk mendukung data deskriptif.

Penelitian diikuti oleh 90 responden dari 93 orang residen Obstetri dan Ginekologi Universitas Gadjah Mada di RSUP Dr. Sardjito Yogyakarta yang memenuhi kriteria inklusi, yaitu sudah pernah melakukan pelayanan obstetri dan ginekologi di kamar bersalin RSUP Dr. Sardjito minimal satu bulan lamanya.

Data penelitian dianalisis dengan analisis univariat, bivariat (uji Chi-Square, analisis korelasi Pearson), dan analisis multivariat (analisis regresi logistik).

\section{HASIL DAN PEMBAHASAN}

Dari 57 butir kuesioner yang ada, dikeluarkan 7 butir kuesioner (butir 4, 5, 6, 27, 30, 42 dan $55)$ dikarenakan adanya missing data yang tidak memungkinkan untuk dilakukan analisis lebih lanjut. Pada uji reliabilitas (alpha Cronbach) didapatkan nilai alpha adalah sebesar 0,862 atau $86,2 \%$. Pemberian nilai pada tiap butir kuesioner menggunakan skala Likert.

Kuesioner tentang pengetahuan keselamatan pasien di kamar bersalin berisi 18 butir. Setelah dilakukan uji alpha Cronbach, didapatkan nilai alpha sebesar 0,702 atau 70,2\%. Apabila dilakukan penelitian yang sama berulang dengan menggunakan kuesioner ini, maka kemiripan hasil yang didapat sebesar 70,2\%. Penilaian pengetahuan yang dianggap baik jika skornya diatas 75 .

Karakteristik responden (tabel 1), yang paling banyak adalah responden yang berusia $\geq 30$ tahun( $58,9 \%)$, berjenis kelamin perempuan $(55,6 \%)$, dengan lama pendidikan $\leq 2$ tahun $(61,1 \%)$, dan sudah pernah mengikuti kursus tentang keselamatan pasien (80\%).

Tabel 1. Karakteristik subyek penelitian

\begin{tabular}{lc}
\hline \multicolumn{1}{c}{ Variabel } & Jumlah $(\%)$ \\
\hline Usia & \\
$<30$ tahun & $37(41,1)$ \\
$\quad \geq 30$ tahun & $53(58,9)$ \\
Jenis Kelamin & \\
$\quad$ Laki-laki & $40(44,4)$ \\
$\quad$ Perempuan & $50(55,6)$ \\
Lama Pendidikan & \\
$\quad \leq 2$ tahun & $55(61,1)$ \\
$\quad>2$ tahun & $35(38,9)$ \\
Kursus tentang patient & \\
safety & \\
Sudah pernah & $72(80)$ \\
Belum pernah & $18(20)$ \\
\hline
\end{tabular}

SAQ mengandung 6 unsur sikap keselamatan. Total rerata butir kuesioner (cut off point) yang diperoleh yaitu sebesar $3,90 \pm 0,34$. Unsur tentang pengenalan stress adalah unsur yang mempunyai nilai di bawah cut off point, yaitu

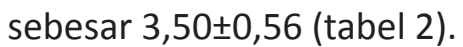

Untuk kualitas kerjasama, nilai yang tinggi dan sangat tinggi adalah antara responden dengan sesama residen $77,7 \%$, dan dokter spesialis obstetri dan ginekologi sekitar 55,5\% (tabel 3). Sedangkan dengan tenaga kesehatan lain nilainya masih rendah. 
Tabel 2. Skor masing-masing unsur dari sikap

\begin{tabular}{lccc}
\hline \multicolumn{1}{c}{ Unsur } & Mean (SD) & Minimum & Maximum \\
\hline 1. Iklim kerjasama tim & $4,00(0,43)$ & 3,0 & 5,0 \\
2. Iklim keselamatan & $4,20(0,44)$ & 2,8 & 4,8 \\
3. Kepuasan kerja & $4,27(0,61)$ & 2,4 & 5,0 \\
4. Pengenalan stress & $3,50(0,56)$ & 1,8 & 4,6 \\
5. Persepsi tentang manajemen & $3,88(0,57)$ & 2,8 & 5,0 \\
6. Kondisi kerja & $3,71(0,38)$ & 2,8 & 4,8 \\
\hline
\end{tabular}

Tabel 3. Kualitas kerjasama responden

\begin{tabular}{lccccc}
\hline \multirow{2}{*}{$\begin{array}{c}\text { Kualitas } \\
\text { kerjasama }\end{array}$} & $\begin{array}{c}\text { Sangat } \\
\text { rendah }\end{array}$ & Rendah & Cukup & Tinggi & Sangat tinggi \\
\cline { 2 - 6 } & $\mathrm{N}(\%)$ & $\mathrm{N}(\%)$ & $\mathrm{N}(\%)$ & $\mathrm{N}(\%)$ & $\mathrm{N}(\%)$ \\
\hline Dokter Obsgin (konsulen) & 0 & $1(1,1)$ & $39(43,3)$ & $30(33,3)$ & $20(22,2)$ \\
Bidan & 0 & $1(1,1)$ & $55(61,1)$ & $28(31,1)$ & $6(6,7)$ \\
Kepala Ruang Bersalin & $1(1,1)$ & $8(8,9)$ & $59(65,6)$ & $16(17,8)$ & $6(6,7)$ \\
Residen & 0 & 0 & $20(22,2)$ & $30(33,3)$ & $40(44,4)$ \\
Asisten Perawat & 0 & $24(26,7)$ & $47(52,2)$ & $12(13,2)$ & $7(7,8)$ \\
Dokter Muda & $1(1,1)$ & $12(13,3)$ & $55(61,1)$ & $18(20)$ & $4(4,4)$ \\
\hline
\end{tabular}

Tabel 4. Hubungan pengetahuan dengan karakteristik responden

\begin{tabular}{|c|c|c|c|c|c|}
\hline \multirow[b]{2}{*}{ Karakteristik } & \multicolumn{2}{|c|}{ Pengetahuan } & \multirow{2}{*}{$\%$ Baik } & \multirow{2}{*}{$\mathrm{RP95 \% Cl}$} & \multirow{2}{*}{$\mathrm{p}$} \\
\hline & Baik & Buruk & & & \\
\hline \multicolumn{6}{|l|}{ Usia } \\
\hline$\geq 30$ tahun & 44 & 9 & 83,0 & $0,93(0,79-1,10)$ & \multirow{2}{*}{0,41} \\
\hline$<30$ tahun & 33 & 4 & 89,2 & 1 & \\
\hline \multicolumn{6}{|l|}{ Jenis kelamin } \\
\hline Perempuan & 46 & 4 & 92,0 & $1,19(0,99-1,43)$ & \multirow{2}{*}{0,052} \\
\hline Laki-laki & 31 & 9 & 77,5 & 1 & \\
\hline \multicolumn{6}{|l|}{ Lama pendidikan } \\
\hline$>2$ tahun & 47 & 8 & 85,5 & $1,1(0,77-1,58)$ & \multirow{2}{*}{0,61} \\
\hline$\leq 2$ tahun & 30 & 5 & 85,7 & 1 & \\
\hline \multicolumn{6}{|l|}{ Kursus patient safety } \\
\hline Pernah & 61 & 11 & 84,7 & $0,81(0,55-1,20)$ & \multirow{2}{*}{0,34} \\
\hline Belum pernah & 16 & 2 & 88,9 & 1 & \\
\hline
\end{tabular}


Pada tabel 4 terlihat hubungan pengetahuan dengan kerakteristik responden. Dengan nilai $p$ yang $>0,05$, maka usia, jenis kelamin, lama pendidikan dan kursus atau tidak tentang keselamatan pasien tidak mempengaruhi pengetahuan responden secara bermakna.

Usia, jenis kelamin, lama pendidikan dan kursus tentang keselamatan pasien juga tidak mempengaruhi sikap responden terhadap keselamatan pasien secara bermakna $(p>0,05)$.
Hubungan antara sikap dengan karakteristik responden ini dapat dilihat pada tabel 5 .

Pengetahuan tentang keselamatan pasien juga tidak mempengaruhi sikap tentang keselamatan pasien pada responden secara bermakna. Ini dapa dilihat pada tabel $6(p>0,05)$.

Pengetahuan tentang keselamatan pasien juga tidak mempengaruhi sikap tentang keselamatan pasien pada responden secara bermakna. Ini dapa dilihat pada tabel7 ( $p>0,05)$.

Tabel 5. Hubungan sikap dengan karakteristik responden

\begin{tabular}{|c|c|c|c|c|c|}
\hline \multirow[b]{2}{*}{ Karakteristik } & \multicolumn{2}{|c|}{ Sikap } & \multirow[b]{2}{*}{ \% Baik } & \multirow[b]{2}{*}{$\mathrm{RP95 \% Cl}$} & \multirow[b]{2}{*}{$\mathrm{p}$} \\
\hline & Baik & Buruk & & & \\
\hline \multicolumn{6}{|l|}{ Usia } \\
\hline$\geq 30$ tahun & 33 & 20 & 62,3 & $1,28(0,87-1,89)$ & 0,20 \\
\hline$<30$ tahun & 19 & 18 & 51,4 & 1 & \\
\hline \multicolumn{6}{|l|}{ Jenis kelamin } \\
\hline Perempuan & 26 & 24 & 52,0 & $0,83(0,58-1,19)$ & 0,32 \\
\hline Laki-laki & 25 & 15 & 62,5 & 1 & \\
\hline \multicolumn{6}{|l|}{ Lama pendidikan } \\
\hline$>2$ tahun & 21 & 14 & 60 & $1,1(0,77-1,58)$ & 0,61 \\
\hline$\leq 2$ tahun & 30 & 25 & 54,5 & 1 & \\
\hline \multicolumn{6}{|c|}{ Kursus tentang patient safety } \\
\hline Pernah & 39 & 33 & 54,2 & $0,81(0,55-1,20)$ & 0,34 \\
\hline Belum pernah & 12 & 6 & 66,7 & 1 & \\
\hline
\end{tabular}

Tabel 6. Hubungan pengetahuan dengan sikap tentang patient safety

\begin{tabular}{|c|c|c|c|c|c|}
\hline \multirow{2}{*}{ Pengetahuan } & \multicolumn{2}{|c|}{ Sikap } & \multirow{2}{*}{$\%$ baik } & \multirow{2}{*}{$\mathrm{RP} 95 \% \mathrm{Cl}$} & \multirow{2}{*}{$p$} \\
\hline & Baik & Buruk & & & \\
\hline Baik & 41 & 36 & 53,2 & $0,69(0,44-1,04)$ & 0,11 \\
\hline Buruk & 10 & 3 & 76,9 & 1 & \\
\hline
\end{tabular}


Tabel 7. Hubungan antara pengetahuan dan sikap dengan mengendalikan faktor-faktor yang mempengaruhi

\begin{tabular}{|c|c|c|c|c|}
\hline & B & $\operatorname{Exp}(B)$ & $95 \% \mathrm{Cl}$ & $\mathrm{p}$ \\
\hline \multicolumn{5}{|l|}{ Pengetahuan } \\
\hline Baik & 0,99 & 2,69 & $0,66-10,90$ & 0,17 \\
\hline \multicolumn{5}{|l|}{ Buruk } \\
\hline \multicolumn{5}{|l|}{ Umur } \\
\hline$\geq 30$ tahun & $-0,42$ & 0,66 & $0,24-1,76$ & 0,40 \\
\hline \multicolumn{5}{|l|}{$<30$ tahun } \\
\hline \multicolumn{5}{|l|}{ Jenis kelamin } \\
\hline Perempuan & $-0,99$ & 0,73 & $0,29-1,81$ & 0,49 \\
\hline \multicolumn{5}{|l|}{ Laki-laki } \\
\hline \multicolumn{5}{|c|}{ Lama pendidikan } \\
\hline$\geq 2$ tahun & $-0,10$ & 0,90 & $0,32-2,60$ & 0,85 \\
\hline \multicolumn{5}{|l|}{$<2$ tahun } \\
\hline \multicolumn{5}{|c|}{ Kursus patient safety } \\
\hline Pernah & $-0,60$ & 0,55 & $0,17-1,84$ & 0,33 \\
\hline Belum perna & & & & \\
\hline
\end{tabular}

Dalam penelitian ini, sebagian besar responden berusia $\geq 30$ tahun, berjenis kelamin perempuan dan mempunyai lama pendidikan $>2$ tahun. Umumnya para tresponden sudah pernah mengikuti kursus tentang keselamatan pasien.

Perempuan lebih memperhatikan isu mengenai keselamatan pasien dari pada lakilaki walaupun perbedaannya tidak terlalu besar. Secara bermakna pelajar laki-laki memiliki pengalaman klinis yang lebih sedikit daripada perempuan pada area obstetri dan ginekologi. ${ }^{5,6}$ Tetapi pada penelitian ini, tidak ada perbedaan bermakna antara perempuan dan laki-laki pada pengetahuan maupun sikapnya tentang keselamatan pasien.

Senior merupakan orang yang dapat menciptakan budaya dan komitmen yang dibutuhkan untuk memecahkan penyebab yang mendasari kesalahan pada sistem medis yang membahayakan pasien. Semakin banyak pengalaman kerja seseorang, maka semakin waspada terhadap praktik yang aman pada institusi dimana mereka bekerja. ${ }^{7}$

Pada penelitian ini, yang dianggap senior adalah responden yang lama pendidikannya $>2$ tahun dan kebanyakan berumur $\geq 30$ tahun. Akan tetapi dengan nilai $p>0,05$, hal ini menjadi tidak bermakna. Sehingga dapat disimpulkan bahwa umur yang lebih dari 30 tahun dan lama pendidikan yang lebih dari 2 tahun tidak mempengaruhi tingkat pengetahuan dan sikap tentang keselamatan pasien dari responden.

Walaupun demikian, senior masih dianggap sebagai tempat bertanya, meminta saran tentang penanganan pasien, mencari jalan keluar dari masalah, seperti komentar dari beberapa residen junior berikut:

"Saya mempunyai senior favorit yang sangat lembut bicaranya sehingga setiap kali ada kesulitan bahkan kesalahan yang 
saya lakukan saya bisa membicarakan dengannya", atau

"Sebelum maju ke konsulen, kadang-kadang saya minta saran dari senior terlebih dahulu".

Menurut Choundry et al. (2005), meskipun secara umum diasumsikan bahwa ilmu dan kemampuan dokter senior lebih baik dari pada dokter junior tapi apabila ilmu tersebut tidak dikembangkan dan diperbaharui maka dokter senior dapat memberikan kualitas pelayanan yang kurang baik ${ }^{8}$. Tetapi pada penelitian ini, tidak ada perbedaan bermakna antara residen junior dan senior dalam tingkat pengetahuan dan sikap tentang keselamatan pasien. Baik residen junior maupun senior memiliki tingkat pengetahuan dan sikap tentang keselamatan pasien yang baik. Hal ini dimungkinkan karena sebagian besar responden yang sudah pernah mengikuti kursus tentang patient safety adalah residen junior sedangkan yang belum pernah mengikuti kursus tapi mempunyai pengetahuan baik dan bersikap baik sebagian besar adalah residen senior. Tingkat pengetahuan yang baik akan meningkatkan sikap yang baik pula sebanyak 2,69 kali walaupun secara statistik tidak bermakna $(p>0,05)$.

Kualitas kerjasama antar responden dan dengan konsulen dinilai lebih baik dibandingkan dengan tenaga kesehatan lainnya (bidan, kepala ruang bersalin, dokter muda dan asisten perawat). Hal ini dimungkinkan karena kebanyakan residen belum tahu sejauh mana tugas, kewajiban dan tanggung jawab tenaga medis yang lain.

Menurut Veltman (2007), keselamatan pasien berdasarkan kepada kepercayaan, komunikasi yang terbuka dan keefektifitasan dari kerja tim interdisipliner. Hal yang mengganggu proses ini dapat menimbulkan ancaman terhadap patient safety. ${ }^{9}$ Begitu juga menurut Pronovost et al. (2011), selain penilaian performa, yang juga dipandang penting adalah menerapkan praktik klinis yang berbasis bukti. Penerapan tersebut membutuhkan kerjasama tim. ${ }^{10}$
Kemudian, dari 6 unsur sikap, unsur pengenalan stress (stress recognition) yang rendah. Besar kemungkinan berhubungan dengan jam kerja residen. Seperti yang dilaporkan oleh Defoe et al., 2001,yaitu adanya jam kerja yang panjang dikalangan residen obstetri dan ginekologi menyebabkan mereka mengalami periode kekurangan waktu untuk tidur. Kelelahan merupakan perhatian utama di kalangan residen yang ingin jam kerja mereka terbatas. ${ }^{11}$

Mengenai jam kerja itu sendiri, beberapa komentar dari responden seperti:

"Kalau boleh, ada libur setelah jaga, karena rasanya belum habis lelah darijaga seminggu di luar kota", atau

"Kerja dengan sistem shift bagi dokter jaga supaya tidak terlalu lelah karena bekerja dalam kondisi mengantuk akan membahayakan pasien".

Peraturan ACGME yang terbaru tidak menyarankan penurunan yang signifikan dalam keseluruhan jam kerja mingguan dari batas saat ini 80 jam. Residen di Eropa bekerja dengan jam kerja lebih sedikit, tidak lebih dari 48 jam per minggu. ${ }^{12}$ Akan tetapi, pengurangan waktu kerja menjadi terlalu pendek akan meningkatkan kejadian error karena miskomunikasi yang terjadi saat pergantian jaga yang menjadi makin sering. ${ }^{13,14}$

Oleh karena itu, diperlukan pengaturan jam kerja dan peningkatan standarisasi serah terima pasien di rumah sakit pendidikan, serta mencari tahu keseimbangan yang tepat antara kondisi kerja yang manusiawi yang memberikan lingkungan belajar yang lebih baik bagi residen dan kualitas perawatan yang tertinggi bagi pasien untuk kemajuan bersama. ${ }^{13,14}$

Masalah komunikasi telah diidentifikasi sebagai faktor utama yang berkontribusi terhadap peningkatan adverse event. The Joint 
Commission on the Accreditation of Healthcare Organizations melaporkan bahwa dari 2455 kejadian sentinel yang terjadi, $70 \%$ adalah kasus yang terjadi akibat kegagalan dalam komunikasi. ${ }^{7}$

Untuk memperbaiki patient safety di ruang bersalin ini, terdapat 10 rekomendasi yang paling banyak diberikan oleh responden saat wawancara, antara lain:

1. Komunikasi dan kerjasama antar petugas kesehatan atau tim jaga untuk ditingkatkan,

2. Kerja dengan sistem shift,

3. Meningkatkan pengetahuan dan keterampilan dokter dan bidan/meningkatkan kompetensi,

4. Monitoring/pengawasan dan pelayanan pasien yang baik,

5. Bekerja berdasarkan SPM, SOP dan tupoksi yang sudah ditetapkan,

6. Disiplin dan bertanggung jawab dengan tugas masing-masing,

7. Cuci tangan yang benar,

8. Pelatihan/kursus tentang patient safety ditingkatkan,

9. Identifikasi pasien yang baik, dan

10. Dibentuk tim untuk menilai medical error (audit medical error).

\section{KESIMPULAN DAN SARAN}

\section{Kesimpulan}

Secara klinis, pengetahuan tentang keselamatan pasien yang baik meningkatkan sikap yang baik tentang keselamatan pasien pada residen obstetri dan ginekologi dalam pelayanan di kamar bersalin RSUP Dr. Sardjito Yogyakarta.

\section{Saran}

1. Diperlukan penelitian lebih lanjut untuk menilai lebih dalam tingkat pengetahuan dan sikap tentang patient safety pada residen untuk pembelajaran yang berkelanjutan dan meningkatkan mutu pelayanan
2. Perlu diadakan penelitian tentang kepuasan pasien sehubungan dengan pengetahuan dan sikap tentang patient safety tenaga kesehatan

3. Perlu adanya penelitian tentang adverse event ataupun medical error yang terjadi sehubungan dengan pengetahuan dan sikap tentang patient safety tenaga kesehatan.

\section{DAFTAR PUSTAKA}

1. WHO. 2007. Patient Safety Solutions Preamble May 2007. WHO Collaborating Centre for patient safety Solutions.

2. The American College of Obstetricians and Gynecologists. 2009. Patient Safety In Obstetrics and Gynecology. Committee Opinion, 447.

3. Stumpf PG, Anderson B, Lawrence H, Schulkin J. 2009. Obsgyn Opinions About Patient Safety. Cost and Liability Remain Problems; Are Mandated Reports a Solution?. Women's Health Issue 19: 8-13

4. Nabhan A, Ahmed-Tawfik MS. 2007. Understanding and Attitudes Towards Patient Safety Concepts in Obstetrics. Intern J of Gyn and Obst 98:212-16

5. Lowe GS. 2008. The Role of healthcare Work Environment in Shaping a Safety Culture. Healthcare Quarterly vol. 11, no. 2

6. Higham J, Steer PJ. 2004. Gender Gap in Undergraduate Experience and Performance in Obstetrics and Gynaecology: Analysis of Clinical Experience Logs. BMJ Health services research 328:142-3.

7. El-Jardali F, Dimassi H, Jama D, Jafaar M, Hamadeh N. 2011. Predictors and Outcomes of Patient Safety Culture in Hospitals. BMC Health Services Research 11; 45 .

8. Choundry NK, Fletcher RH, Soumerai SB. 2005. Systematic Review: The Relationship Between Clinical Experience and Quality of health Care. Annals of Internal Medicine vol 162, no. 4

9. Veltman LL. 2007. Disruptive behavior in obstetrics: a hidden threat to patient safety. Am J Obstet Gynecol 196: 587.e5

10. Pronovost PJ, Holzmueller G, Ennen CS, Fox HF. 2011. Patient Safety Series Overview of progress in patient safety. Am J of Obstet Gyn 1:5-10 
11. Defoe M, Deidre L, Michael, Holzman B, Gerald, Carpentieri MA, Andrea, Schulkin, Jay. 2001. Long Hours and Little Sleep: Work Schedules of Residents in Obstetric and Gynecology. ACOG. 97: 1015-1018

12. Agency for Healthcare Research and Quality.2012. Physician Work Hours and Patient Safety. U.S. Department of Health and Human Services.

13. Siferlin A. 2013. Fewer Hours for Doctors in Training Leading to More mistakes. Time inc.
14. Starmer AJ, Sectish TC, Simon DW, Keohane C, Mc Sweeney ME, Chung EY, Yoon CS, Lipsitz SR, Wassner AJ, Harper MB, Landrigan CP. 2013. Rates of Medical Errors and Preventable Adverse Events Among Hospitalized Children Following Implementation of Resident Handoff Bundle. The Journal of The American Medical Association, vol. 310, no. 21. 